\title{
A Pole Assignment Type of Autopilot Using the RPE Method
}

\author{
Duc-Hung NGUYEN* and Kohei OHTSU**
}

\author{
逐次予測誤差法を用いた極配置制御型 \\ オートパイロットに関する研究
}

Nguyen Duc Hung · 大津 皓平

\begin{abstract}
This paper presents a new method of designing a self-tuning pole assignment (PA) type of autopilot for ships. The design method applies the recursive prediction error (RPE) algorithm as an online estimator linking to the self-tuning pole assignment algorithm to construct an adaptive autopilot. Main tasks of designing a robust pole assignment type of autopilot are to model the ship dynamic system in an suitable form and to construct the control algorithm. To calculate control gains of the pole assignment control type of autopilot is often based on the ship steering dynamic coefficients identified by an appropriate online estimation method. The new design method is developed from the design method of the conventional pole assignment type of autopilot which was proposed by D.H. Nguyen et al. by applying the recursive least squares (RLS) algorithm linking to the pole assignment control algorithm. Full-scale experiments aboard the training ship at sea are briefly described. The pole assignment type of autopilot using the RPE method has good steering characteristics for course-keeping and course-changing control of ship.
\end{abstract}

\section{Introduction}

Designing a computer-based autopilot system for marine vehicles is always a challenging problem in marine control engineering. According to the self-tuning control theory, a self-tuning controller can be constructed by a combination of an online estimation algorithm with an appropriate control law. The authors proposed a self-tuning autopilot by linking the RLS algorithm to the pole assignment control law ${ }^{(18)}$. The conventional pole assignment type of autopilot had good steering characteristics for course-keeping and coursechanging. However, this design method had to meet with an issue of dividing by zero or singularity of matrix in ill condition ${ }^{(12)(13)}$. And the new autopilot based on the RPE method can avoid this difficulty. In this paper, the authors discuss a new method of designing a self-tuning autopilot for ships by a combination of the recursive prediction error algorithm with the pole assignment control law.

The RPE method applied to estimate parameters of a linear dynamic system was first proposed by L. Ljung and T. Soderstrom ${ }^{(8)(9)(10)}$. Since then, the method has been developed into a nonlinear form by Gavel and Azevedo and then applied to identification of ship hydrodynamics by W.W Zhou and Blanke in both linear and nonlinear versions. The RPE techniques were used for identification of both linear and nonlinear marine systems with good results. It was proved that

* Student Member: Graduate School of Mercantile Marine Science and Technology, Tokyo University of Mercantile Marine. 2-1-6 Etchyujima, Koto-ku, Tokyo 135-8533

** Member: Tokyo University of Mercantile Marine. 2-1-6 Etchyujima, Koto-ku, Tokyo 135-8533 
estimated ship hydrodynamic coefficients had the good convergence according to W.W. Zhou and M. Blanke ${ }^{(19)(20)(21)}$. However, the RPE method might not have been applied to identify ship steering dynamics and combined to a control law to design the ship's autopilot system. The authors have applied the RPE method to identify the ship steering dynamics and then used the identified parameters to design a ship autopilot system by the self-tuning pole assignment control theory.

The motivation for applying the RPE method is that when the authors designed a self-tuning pole assignment type of autopilot for ships by using the RLS method to estimate parameters of an ARX model of ship, there was a problem that one of estimated parameters tended to zero. Consequent$1 y$, when calculating the control gain this caused the issue of dividing by zero or singularity of the inverse matrix. Then, the control was unstable. The authors circumvented the issue by pre-fixing one parameter or modifying the algorithm as stated in their works ${ }^{(11)(12)}$. The authors would like to find a more suitable identification method with more accuracy in estimated parameters to design a robust control system for ships. The RPE method is a choice because it has the property of good convergence of estimates and can be applied to both linear and nonlinear dynamic systems as many other authors stated in their works.

An RPE method-used pole assignment autopilot for course-keeping and -changing has been designed and its steering performance has been verified by computer simulations and full-scale experiments aboard the training ship Shioji Maru of Tokyo University of Mercantile Marine (TUMM) at sea. The main purposes of the work in the paper are:

-to formulate the pole assignment control algorithm by applying the RPE technique

-to actually test the performance of the RPEM -used pole assignment autopilot by full-scale experiments

General features of the new autopilot for course -keeping and course-changing are reported. In this paper, Sect. 2 briefly describes the self-tuning control algorithm including the RPE algorithm and pole assignment control algorithm. Sect.3 describes full-scale experiments and Sect.4 gives some conclusions and future works.

\section{Control Algorithm}

The main task of designing the self-tuning pole assignment autopilot for ships is to construct an appropriate identification algorithm so that it is possible to online estimate the ship steering dynamical coefficients and to automatically change them to meet a particular requirement such as course-keeping and course-changing. The aim of the self-tuning pole assignment control is to exactly match the closed-loop characteristic equation of a feedback system to some desired form. The key idea of the self-tuning control is to shift the open loop poles to some desired set of closed-loop poles. In this section, the control algorithm applying the RPE algorithm linking to the pole assignment control algorithm to construct a self-tuning autopilot for ships is briefly described.

\subsection{Recursive Prediction Error Algorithm}

In general, assuming that a vessel is a dynamic system of an SISO (single-input single-output) linear discrete-time ARX (Auto-Regressive eXogenous) model as follows.

$$
\mathrm{A}\left(\mathrm{z}^{-1}\right) \mathrm{y}(\mathrm{t})=\mathrm{B}\left(\mathrm{z}^{-1}\right) \mathrm{u}(\mathrm{t}-\mathrm{k})+\mathrm{e}(\mathrm{t})
$$

where $\mathrm{k}$ is time delay, $\mathrm{y}(\mathrm{t})$ and $\mathrm{u}(\mathrm{t}-\mathrm{k})$ are measured output and input, respectively, $e(t)$ is zero mean white noise and $\mathrm{A}\left(\mathrm{z}^{-1}\right)$ and $\mathrm{B}\left(\mathrm{z}^{-1}\right)$ are polynomials of $z^{-1}$ which is the backward shift operator $z^{-1} y(t)=y(t-i)$, and defined by

$$
\begin{aligned}
& \mathrm{A}\left(z^{-1}\right)=1+\mathrm{a}_{1} z^{-1}+\mathrm{a}_{2} z^{-2}+\ldots+\mathrm{a}_{\mathrm{m}} \mathrm{z}^{-\mathrm{m}} \\
& \mathrm{B}\left(z^{-1}\right)=\mathrm{b}_{0}+\mathrm{b}_{1} z^{-1}+\mathrm{b}_{2} z^{-2}+\ldots+\mathrm{b}_{\mathrm{n}} z^{-\mathrm{n}}
\end{aligned}
$$

where $\mathrm{m}$ and $\mathrm{n}$ are orders of $\mathrm{A}$-polynomial and $\mathrm{B}$ -polynomial, respectively and can arbitrarily be chosen or determined by some statistical method such as AIC method. In this paper $m$ and $n$ were arbitrarily chosen. The system (1) can be expressed in the matrix form.

$$
\mathrm{y}(\mathrm{t})=\theta \varphi+\varepsilon(\mathrm{t})
$$

where $\theta=\left[a_{1}, a_{2}, \ldots a_{m}, b_{0}, b_{1}, \ldots, b_{n}\right]$ is the vector of unknown parameters and $\varphi=\left[-\mathrm{y}\left(\mathrm{t}^{-1}\right),-\mathrm{y}\right.$ $\left(\mathrm{t}^{-2}\right), \ldots, \quad-\mathrm{y}(\mathrm{t}-\mathrm{m}), \mathrm{u}(\mathrm{t}-\mathrm{k}), \mathrm{u}\left(\mathrm{t}-\mathrm{k}^{-1}\right), \ldots, \mathrm{u}(\mathrm{t}-$ $\mathrm{k}-\mathrm{n})]^{\mathrm{T}}$ is the vector of input and output measure- 
ments, and $\varepsilon(t)$ is error.

The RPE method is to minimize the following criterion function

$$
\mathrm{V}(\theta)=\frac{1}{2} \varepsilon^{\mathrm{T}}(\mathrm{t}) \Lambda^{-1}(\mathrm{t}) \varepsilon(\mathrm{t})
$$

where $\Lambda(t)$ is a positive definite matrix, and a Gauss-Newton search direction is chosen as

$$
\mathrm{f}(\mathrm{t})=\mathrm{H}^{-1}(\mathrm{t}) \psi(\mathrm{t}, \theta) \Lambda^{-1}(\mathrm{t}) \varepsilon(\mathrm{t}, \theta)
$$

where $\mathrm{H}(\mathrm{t})$ is the Hessian, the second derivative of the criterion function with respect to $\theta$, and $\psi$ $(t, \theta)$ is the gradient of predicted output with respect to $\theta$. In short, the RPE method using the Gauss-Newton search direction to estimate the parameter $\theta$ of (4) is summarized as follows ${ }^{(8)(9)(10)(19)(20)(21)}$.

1) Step $1: \varepsilon(\mathrm{t})=\mathrm{y}(\mathrm{t})-\hat{\mathrm{y}}(\mathrm{t})$

2) Step $2: \Lambda(t)=\Lambda(t-1)+\alpha(t)\left[\varepsilon \varepsilon^{\mathrm{T}}-\right.$

$$
\Lambda(t-1)]
$$

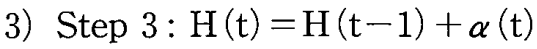

$$
\left[\psi(\mathrm{t}) \Lambda^{-1}(\mathrm{t}) \psi^{\mathrm{T}}(\mathrm{t})-\mathrm{H}(\mathrm{t}-1)\right]
$$

4) Step 4: $\theta(\mathrm{t})=\theta(\mathrm{t}-1)+\alpha(\mathrm{t}) \mathrm{H}^{-1}(\mathrm{t}) \psi(\mathrm{t})$

$$
\Lambda^{-1}(\mathrm{t}) \varepsilon(\mathrm{t})
$$

5) Step $5: \hat{y}(t+1)=\theta(t) \varphi(t+1)$

6) Step 6: Calculate the gradient of predicted output by

$$
\psi(\mathrm{t})=\left[\frac{\mathrm{d}}{\mathrm{d} \theta} \hat{\mathrm{y}}(\mathrm{t}, \theta)\right]^{\mathrm{T}}
$$

7) Step 7 : To update data and loop back to the step 1.

It should be noted that $\alpha$ is the step size factor and given by Ljung, Soderstrom, Zhou and Blanke below $^{(8)(9)(10)(19)(20)(21)}$.

$$
\alpha(\mathrm{t})=\frac{1}{1+\mathrm{t}}
$$

\subsection{Self-tuning Pole Assignment Control Algorithm}

This section discusses the pole assignment control algorithm to be linked to the abovementioned RPE algorithm to construct a selftuning autopilot for ships.

In general, assuming that the controller is of the form as follows.

$$
\mathrm{Fu}(\mathrm{t})=\mathrm{Hr}(\mathrm{t})-\mathrm{Gy}(\mathrm{t})
$$

where $r(t)$ is a reference signal, and $F\left(z^{-1}\right), G$ $\left(z^{-1}\right)$ and $\mathrm{H}\left(z^{-1}\right)$ are defined by

$$
\begin{aligned}
& \mathrm{F}\left(z^{-1}\right)=1+\mathrm{f}_{1} z^{-1}+\mathrm{f}_{2} z^{-2}+\ldots+\mathrm{f}_{\mathrm{f}} z^{-\mathrm{f}} \\
& \mathrm{G}\left(z^{-1}\right)=\mathrm{g}_{0}+\mathrm{g}_{1} z^{-1}+\mathrm{g}_{2} z^{-2}+\ldots+\mathrm{g}_{\mathrm{g}} z^{-\mathrm{g}} \\
& \mathrm{H}\left(z^{-1}\right)=\mathrm{h}_{0}+\mathrm{h}_{1} z^{-1}+\mathrm{h}_{2} z^{-2}+\ldots+\mathrm{h}_{\mathrm{h}} z^{-\mathrm{h}}
\end{aligned}
$$

By combining the controller and system equations, one can obtain the closed-loop description

$$
\left(\mathrm{FA}+z^{-1} \mathrm{BG}\right) \mathrm{y}(\mathrm{t})=z^{-1} \mathrm{BHr}(\mathrm{t})+\mathrm{Fe}(\mathrm{t})
$$

In this paper, the authors propose a new method of designing an autopilot system for ships by using the parameters $(\theta)$ estimated by the above -mentioned RPE algorithm and the self-tuning pole assignment control law to compute the control signal (rudder). According to the self-tuning pole assignment control theory, poles of the closed-loop equation (18) are assigned to the desired locations by a desired pole set polynomial $\mathrm{T}$, given by

$$
\mathbf{T}=1+\mathrm{t}_{1} \mathrm{z}^{-1}+\mathrm{t}_{2} \mathrm{z}^{-2}+\ldots+\mathrm{t}_{\mathrm{t}} \mathrm{z}^{-\mathrm{t}}
$$

Then, the following polynomial identity is obtained.

$$
\mathrm{FA}+\mathrm{z}^{-1} \mathrm{BG}=\mathbf{T}
$$

The coefficients of polynomials $F$ and $G$ are

Feedback

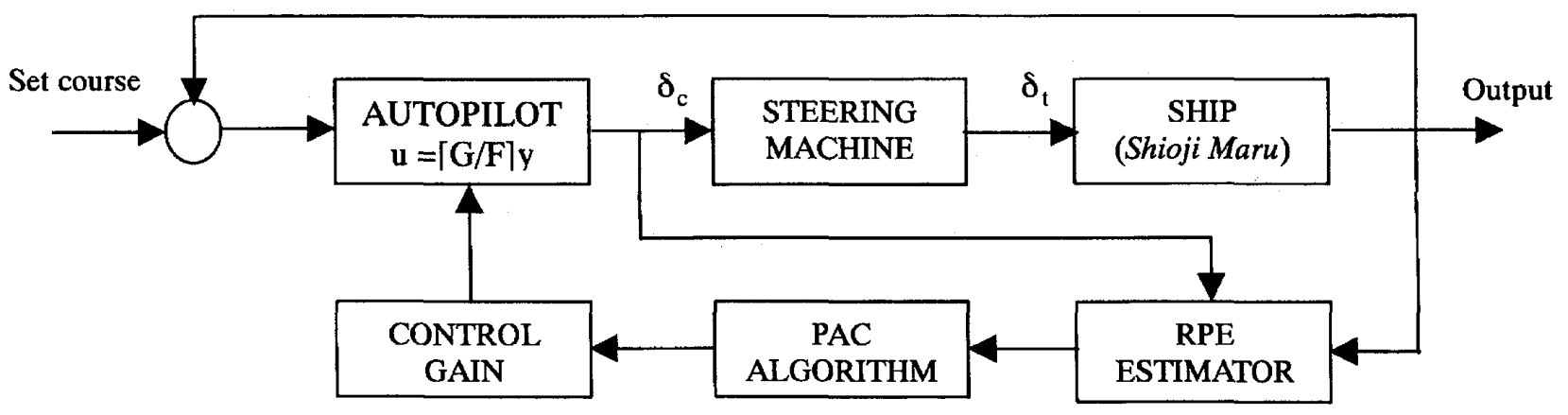

Figure 1 Block diagram of the PA autopilot $\left(\delta_{\mathrm{c}}=\right.$ command rudder, $\delta_{\mathrm{t}}=$ true rudder $)$ 
selected by (20). It should be noted that for a unique solution to (20) the degrees $f, g$ should be selected as $\mathrm{f}=\mathrm{n}, \mathrm{g}=\mathrm{m}-1 \quad(\mathrm{~m} \neq 0)$, provided $\mathrm{A}, \mathrm{B}$ have no common zeroes, i.e. $\mathrm{A}$ and $\mathrm{B}$ are $\mathrm{co}^{-}$ prime. The number of parameters is $M=m+n+1$. In addition, the number of $\mathbf{T}$-polynomial coefficients should satisfy the inequality $\mathrm{t} \leqq \mathrm{m}+\mathrm{n}-\mathrm{q}$, where $\mathrm{q}=0$ in the case of the above-mentioned ARX model. Interested readers can refer to P.E. Wellstead et al. ${ }^{(18)}$.

From (20), control gains or coefficients of $F$ and $\mathrm{G}$ are resulted in the following equation.

$$
\mathbf{D} \Phi_{\mathrm{C}}=\mathbf{b}
$$

where $\mathbf{b}$ is a vector formed by the coefficients of $T$ and the estimated parameters of the polynomial $A, \Phi_{C}$ is the control gain vector including the coefficients of $\mathbf{F}$ and $G$ and $\mathbf{D}$ is a matrix formed by estimated parameters of $\mathrm{A}$ and $\mathrm{B}$.

Finally, the command rudder is calculated by the following equation

$$
\mathrm{u}(\mathrm{t})=\left[\mathrm{H}_{\mathrm{c}} \mathrm{r}(\mathrm{t})-\mathrm{Gy}(\mathrm{t})\right] / \mathrm{F}
$$

where $\mathrm{H}_{\mathrm{C}}$ is the polynomial $\mathrm{H}$ selected as $\mathrm{H}_{\mathrm{C}}=$ $[\mathrm{T} / \mathrm{B}]_{\mathrm{z}=1}$ to cancel the noise in the disturbance term $^{(18)}$.

The remaining tasks of constructing the autopilot are to select the design parameters such as the desired pole set polynomial $\mathrm{T}$, sampling time and so on.

\subsection{Block Diagram and Simulink Model of the Autopilot System}

The pole assignment type of autopilot using the RPE algorithm for experiment is shown in Fig.1. The control program is a MATLAB/Simulink model as shown in Fig.2.

\section{Full-scale Experiments and Results}

\subsection{The Training Ship Shioji Maru}

The ship's autopilot designed based on the above-mentioned algorithm was verified by the full-scale experiments aboard the training ship Shioji Maru of TUMM at sea. Particular dimensions of the Shioji Maru are shown in Table 1. The control program is coded in a MATLAB/

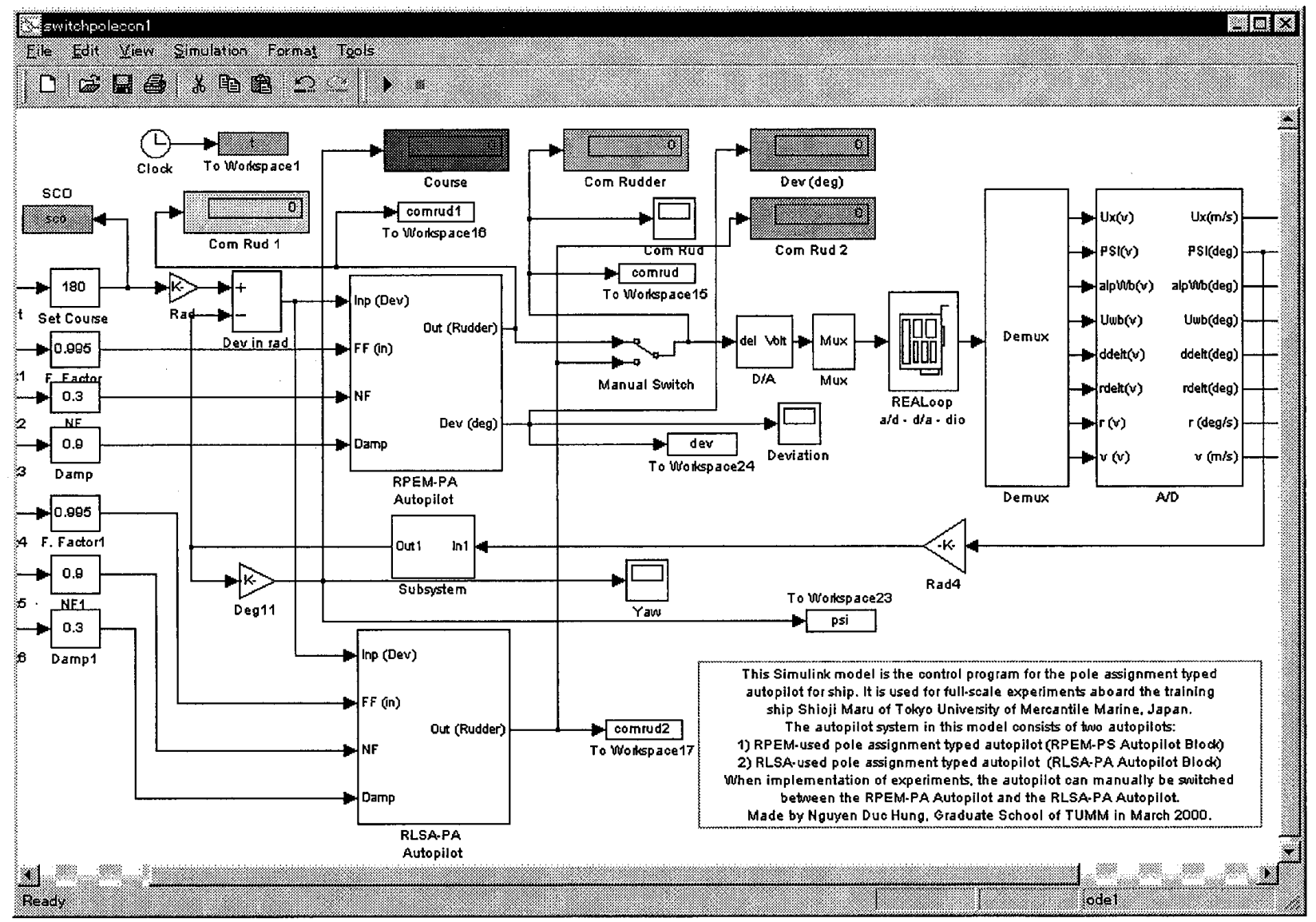

Figure 2 Simulink model of control program for experiments 
Simulink model and is executed on a Pentium PC with REALoop. Additionally, REALoop is a software and hardware kit of Xanalog Corporation of Switzerland, running in the Simulink simulation environment of the MathWorks Incorporation. REALoop transforms Simulink into a user-friendly real-time simulation system, offering real-time interation with the real world from within a Simulink model ${ }^{(13)}$. The control system with REALoop aboard the training ship is shown in Fig.3. Some representative full-scale experiments and results will be described in details below.

Table 1 Particular dimensions of the Shioji Maru

\begin{tabular}{|l|c|l|c|}
\hline Length & $46.00[\mathrm{~m}]$ & Breadth & $10.00[\mathrm{~m}]$ \\
\hline Draft & $3.00[\mathrm{~m}]$ & Displacement & $717.52[\mathrm{t}]$ \\
\hline GRT & $425.00[\mathrm{t}]$ & Propeller & CPP \\
\hline Bow Thruster & $2.4[\mathrm{t}]$ & Stern Thruster & $1.8[\mathrm{t}]$ \\
\hline
\end{tabular}

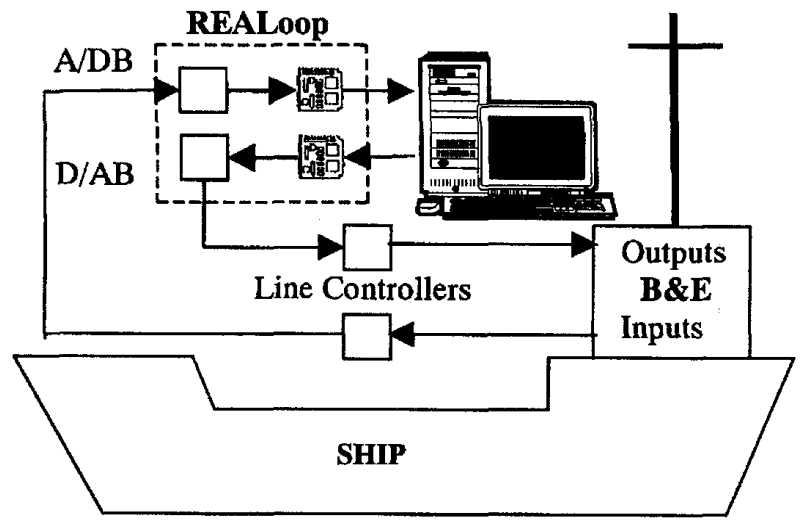

Figure 3 Control system with REALoop on ship $(\mathrm{A} / \mathrm{DB}=\mathrm{A} / \mathrm{D}$ Board, $\mathrm{D} / \mathrm{AB}=\mathrm{D} / \mathrm{A}$ Board, $\mathrm{B} \& \mathrm{E}=$ Bridge \& Engine)

\subsection{Description of Experiments and Results}

Experiments were performed for a specific ship model with a selected number of parameters. Applying the above-mentioned control algorithm in the case of $n=3, m=2, k=1$, the desired pole polynomial $T=1+t_{1} z^{-1}+t_{2} z^{-2}$, of which coefficients are calculated by the vibration equations.

$$
\begin{aligned}
& \mathrm{t}_{1}=-2 \exp (-\xi \omega \tau) \cos \left\{\tau \omega\left(1-\xi^{2}\right)^{1 / 2}\right\} \quad \& \\
& \mathrm{t}_{2}=\exp (-2 \xi \omega \tau)
\end{aligned}
$$

where $\xi, \omega, \tau$ are damping factor, natural frequency and sampling time, respectively. By selecting the damping factor, natural frequency and sampling time such that the desired poles of the system are inside the unit circle on the complex $z$ - plane ${ }^{(4)(18)}$, the step response of the control system can be specified by designer. The number of parameters of the assumed model for experiments is $\mathrm{M}=3+2+1=6$.

The orders of the polynomials $F$ and $G$ are selected as $f=2, g=2$, respectively. The control gain is resulted in the following linear system of equations.

$$
\mathbf{D} \Phi_{\mathrm{C}}=\mathbf{b}
$$

where $\mathbf{b}=\left[\left(\mathrm{t}_{1}-\mathrm{a}_{1}\right),\left(\mathrm{t}_{2}-\mathrm{a}_{2}\right),\left(-\mathrm{a}_{3}\right), 0,0\right]^{\mathrm{T}}, \Phi_{\mathrm{c}}=$ $\left[f_{1}, f_{2}, g_{0}, g_{1}, g_{2}\right]^{\mathrm{T}}$, the vector of control gains and D is a matrix formed by estimated parameters as in (25).

$$
D=\left[\begin{array}{ccccc}
1 & 0 & b_{0} & 0 & 0 \\
a_{1} & 1 & b_{1} & b_{0} & 0 \\
a_{2} & a_{1} & b_{2} & b_{1} & b_{0} \\
a_{3} & a_{2} & 0 & b_{2} & b_{1} \\
0 & a_{3} & 0 & 0 & b_{2}
\end{array}\right]
$$

Table 2 Statistical values of estimated parameters (Exp. 1)

\begin{tabular}{|c|c|c|c|c|}
\hline \multirow{2}{*}{ Parameters } & \multicolumn{4}{|c|}{ Experiment 1 } \\
\cline { 2 - 5 } & Mean & Max & Min & Final \\
\hline $\mathrm{a}_{1}$ & -0.3111 & 1.1419 & -0.8732 & -0.4108 \\
\hline $\mathrm{a}_{2}$ & 0.3037 & 1.7219 & -2.3464 & 0.2366 \\
\hline $\mathrm{a}_{3}$ & -2.4297 & 2.0366 & -5.4389 & -2.0581 \\
\hline $\mathrm{b}_{0}$ & -1.8280 & 4.7336 & -6.4785 & -1.4148 \\
\hline $\mathrm{b}_{1}$ & 0.3902 & 1.5348 & -0.5817 & 0.1905 \\
\hline $\mathrm{b}_{2}$ & -0.3375 & -0.0089 & -0.5719 & -0.2553 \\
\hline
\end{tabular}

Table 3 Statistical values of estimated parameters (Exp. 2)

\begin{tabular}{|c|c|c|c|c|}
\hline \multirow{2}{*}{ Parameters } & \multicolumn{4}{|c|}{ Experiment 2 } \\
\cline { 2 - 5 } & Mean & Max & Min & Final \\
\hline $\mathrm{a}_{1}$ & -0.3939 & -0.2848 & -0.6604 & -0.4420 \\
\hline $\mathrm{a}_{2}$ & -1.4261 & -1.3237 & -2.3455 & -1.3292 \\
\hline $\mathrm{a}_{3}$ & 1.1122 & 2.0403 & 1.0270 & 1.0270 \\
\hline $\mathbf{b}_{0}$ & -0.0846 & 0.0453 & -0.1167 & -0.0836 \\
\hline $\mathbf{b}_{1}$ & 0.4235 & 0.5127 & 0.0034 & 0.3643 \\
\hline $\mathbf{b}_{2}$ & 0.1364 & 0.1653 & -0.0090 & 0.1247 \\
\hline
\end{tabular}

Table 4 Statistical values of estimated parameters (Exp. 3)

\begin{tabular}{|c|c|c|c|c|}
\hline \multirow{2}{*}{ Parameters } & \multicolumn{4}{|c|}{ Experiment 3 } \\
\cline { 2 - 5 } & Mean & Max & Min & Final \\
\hline $\mathrm{a}_{1}$ & -0.2525 & -0.0459 & -0.6604 & -0.3012 \\
\hline $\mathrm{a}_{2}$ & -1.3778 & -1.3023 & -2.3455 & -1.3044 \\
\hline $\mathrm{a}_{3}$ & $\mathbf{1 . 0 0 7 7}$ & 2.0403 & 0.9255 & 0.9255 \\
\hline $\mathrm{b}_{0}$ & 0.1395 & 0.1949 & -0.0203 & 0.1191 \\
\hline $\mathrm{b}_{1}$ & 0.3166 & 0.5914 & $\mathbf{0 . 0 0 3 4}$ & 0.2736 \\
\hline $\mathrm{b}_{2}$ & 0.0398 & 0.1638 & -0.0090 & $\mathbf{0 . 0 3 8 6}$ \\
\hline
\end{tabular}



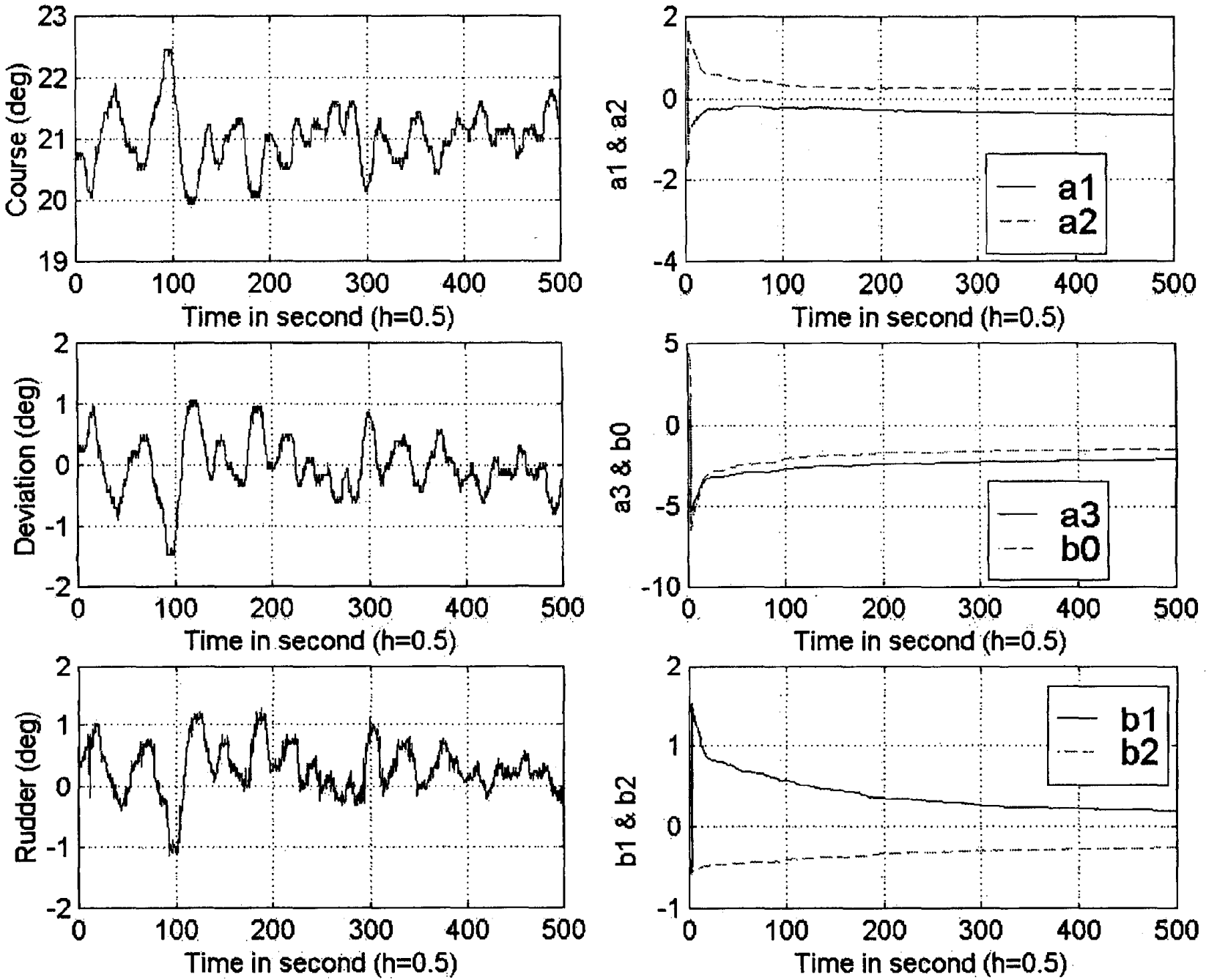

Figure 4 Time series of ship responses and estimated parameters (Experiment 1)

By assuming the reference point $r(t)$ is zero, the rudder signal can be calculated by

$$
\begin{aligned}
\mathrm{u}(\mathrm{t})= & -\mathrm{f}_{1} \mathrm{u}(\mathrm{t}-1)-\mathrm{f}_{2} \mathrm{u}(\mathrm{t}-2)-\mathrm{g}_{0} \mathrm{y}(\mathrm{t}) \\
& -\mathrm{g}_{1} \mathrm{y}(\mathrm{t}-1)-\mathrm{g}_{2} \mathrm{y}(\mathrm{t}-2)
\end{aligned}
$$

The remaining task is to select appropriate initial settings and design parameters such as natural frequency and damping factor.

Before implementation of full-scale experiments at sea, computer simulation was performed for the training ship Shioji Maru by using the non -linear mathematical model known as MMG model. Design parameters were primarily selected by simulation.

\subsection{Experiment Results}

Experiment 1: Autopilot for course-keeping. The design parameters of the autopilot were chosen as: natural frequency $=0.9$, damping factor $=0.9$, sampling time $=0.5$ sec., initial Hessian
$H=1000 \times I_{6}$ and $\Lambda=2$. Set course was set at 21 degrees. Time series of ship responses and estimated parameters are shown in Fig.4. Some statistical values of estimated parameters are as in Table 2.

Looking at Fig.4, the course was kept very stable, the maximum deviation between the true course and the set course was only 1.4512. No parameters became zero. Estimated parameters converged.

Experiment 2: Autopilot for course-keeping and course-changing. The design parameters of the autopilot were chosen as : natural frequency $=$ 0.3 , damping factor $=0.9$, sampling time $=0.5 \mathrm{sec}$., initial Hessian $\mathrm{H}=1000 \times \mathrm{I}_{6}$ and $\Lambda=3.5$. Set course was set at 180 degrees, and changed to 170 degrees, then returned to 180 degrees. Time series of ship responses and estimated parameters are shown in Fig.5. Some statistical values of esti- 

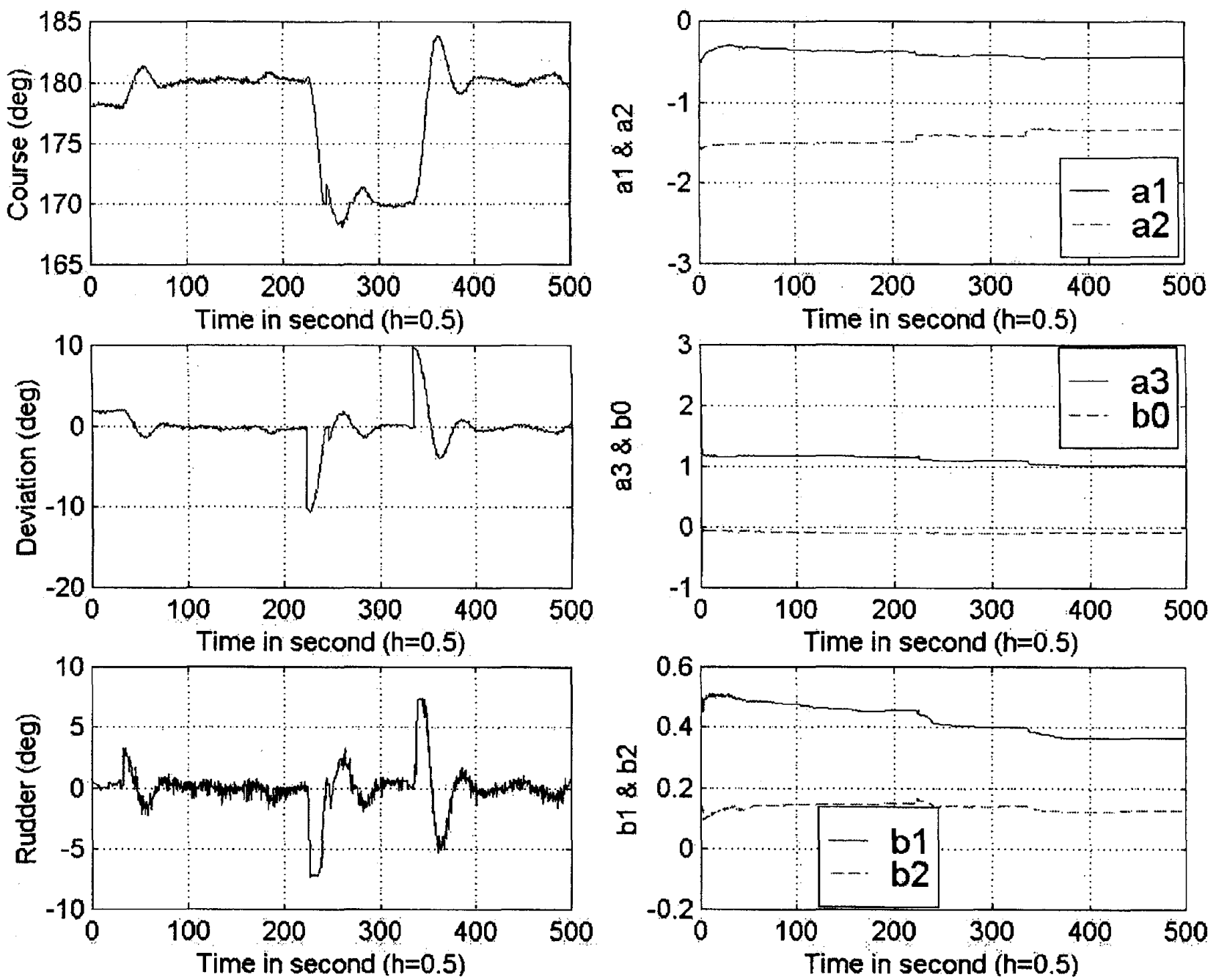

Figure 5 Time series of ship responses and estimated parameters (Experiment 2)

mated parameters are as in Table 3.

Looking at Fig.5, the ship course was controlled as expected. However, in this experiment, when changing the course, the overshoot (see time series of course) was a little bit larger (maximum overshoot was 3.8870 degrees) than expected. Estimated parameters seemed to converge better than those in the experiment 1 . The converge values of estimated parameters seemed to vary when the course was changed.

Experiment 3: Autopilot for course-keeping and course-changing. The design parameters of the autopilot were chosen as : natural frequency = 0.3 , damping factor $=0.9$, sampling time $=0.5 \mathrm{sec}$, initial Hessian $H=1000 \times I_{6}$ and $\Lambda=3.5$. Set course was set at 180 degrees, and changed to 190 degrees, then returned to 180 degrees. Time series of ship responses and estimated parameters are shown in Fig.6. Some statistical values of estimated parameters are as in Table 4.
Looking at Fig.6, the overshoot of the true course when changing the course in this experiment was 2.0215, smaller than that of the experiment 2. Estimated parameters converged well.

General speaking, the RPE method-used pole assignment type of autopilot was robust and adaptive to changes of the environment. By using the RPE algorithm, all parameters of the assumed ship model were estimated and converged well. No parameters became to zero and no singularity issue occurred when online solving the equation (21) or (24) in comparison with the pole assignment type of autopilot using the RLS algorith$\mathrm{m}^{(11)(12)}$. The ship course was kept stable as expected. An attempt was made to reduce the overshoot by choosing the design parameters such as damping factor, natural frequency and so on during implementation of full-scale experiments. 

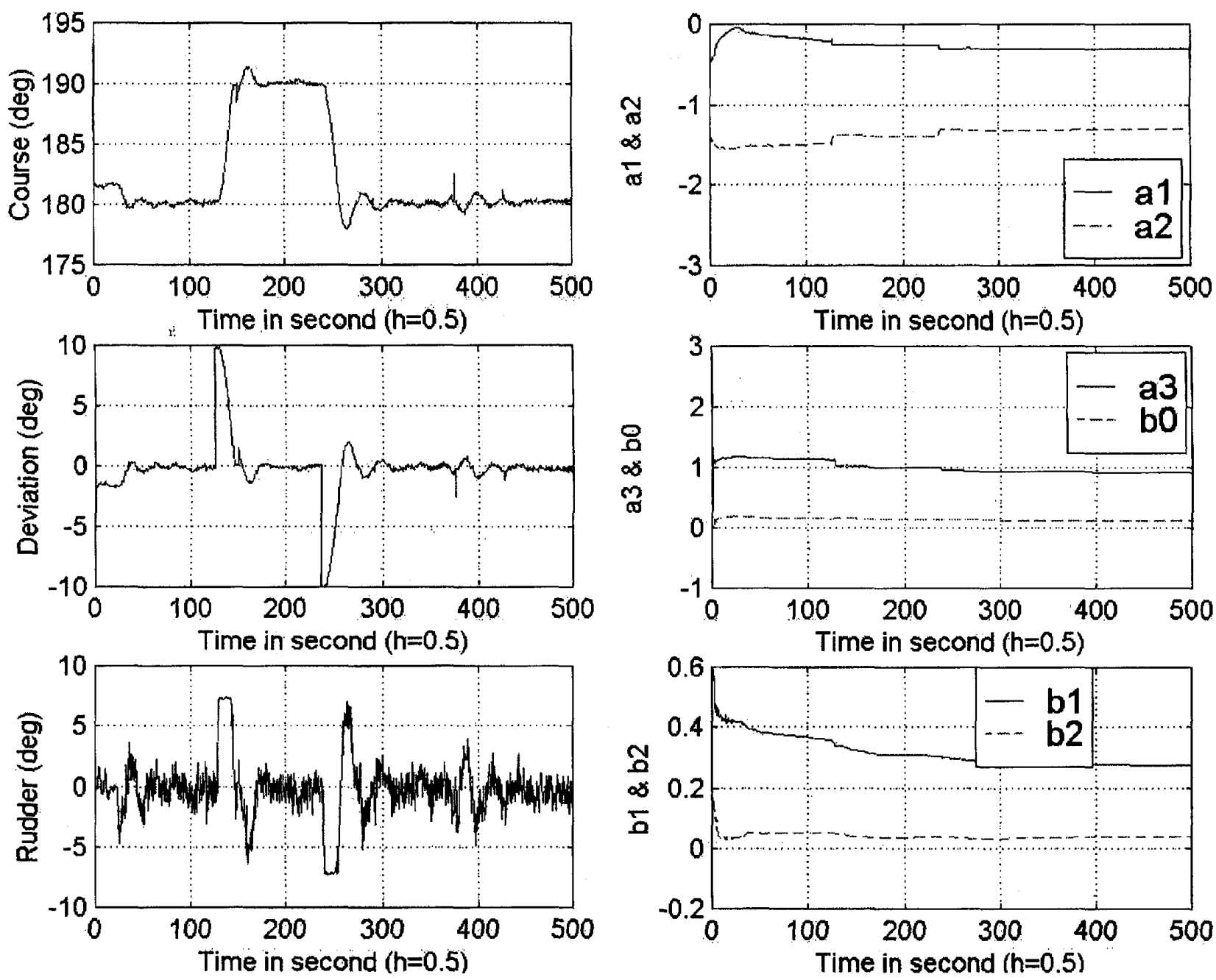

Figure 6 Time series of ship responses and estimated parameters (Experiment 3 )

\section{Conclusions and Future Works}

It was found that the RPE algorithm was good for the online estimation of ship steering dynamics. It was possible to estimate all assumed parameters of the ship model. The pole assignment control type of autopilot was adaptive to the changes of the environment and had good steering characteristics for course-keeping and coursechanging. The new autopilot would be more robust and better than the conventional pole assignment type of autopilot using the RLS algorithm. In comparison with the conventional design method, no issue of singularity occurred.

Further study on this type of the control design method should be done. Some future works would be proposed below.

- to carry out full-scale experiments to compare the RPE method-used pole assignment type of autopilot with the RLS method-used pole assignment autopilot in order to find which has the better steering characteristics

- to find a method to determine the orders of polynomials in the mathematical model and to choose the most appropriate model of ship steering dynamics.

- to develop this type of autopilot into a tracking controller or a new automatic berthing system for ships.

\section{Acknowledgement}

The sincere acknowledgement would be expressed to Associate Professor I. Hatta, the captain, to Mr. N. Hirose, the chief engineer and to all crew members of the training ship Shioji Maru of Tokyo University of Mercantile Marine for their enthusiastic helpings in full-scale experiments. Thanks would also be expressed to Mr. J.S. Park and Mr. H. Fukuda of Graduate School of Tokyo University of Mercantile Marine, to Mr. T. Na- 
katani of Toyama National College of Maritime Technology for their interesting discussions.

\section{References}

(1) Astrom, K.J. and C.G. Kallstrom : Identification of Ship Steering Dynamics, Automatica, Vol.12, pp.9-22, Pergamon Press, UK (1976).

(2) Astrom, K.J. and B. Wittenmark : Computer Controlled Systems: Theory and Design, Prentice-Hall Inc., Englewood Cliffs, New Jersey, USA (1984).

(3) Astrom, K.J. and B. Wittenmark: Adaptive Control, Addison-Wesley, USA (1989).

(4) Cadzow, J.A.: Discrete-time Systems. Prentice-Hall (1973).

(5) Fossen, T.I. : Guidance and Control of Ocean Vehicles, John Wiley and Sons Ltd., UK (1994).

(6) Holzhuter, T. : A High Precision Track Controller for Ships, IFAC 11th Triennial World Congress, pp.425-430, Talinn, Estonia, Russia (1990).

(7) Kallstrom, C.G., K.J. Astrom, N.E. Thorell, J. Eriksson and L. Sten: Adaptive Autopilots for Tankers, Automatica, Vol.15, pp.241-254, Pergamon Press, UK (1979).

(8) Ljung, L.: Asymptotic Behavior of the Extended Kalman Filter as a Parameter Estimator for Linear Systems, IEEE Transactions on AC, Vol.24 (1), pp.36-50, UK (1979).

(9) Ljung, L. and T. Soderstrom: Theory and Practice of Recursive Identification, MIT Press, MA, USA (1983).

(10) Ljung, L.: System Identification : Theory for the User, Prentice-Hall, New Jersey, USA (1987).

(11) Mizuno, H., T. Okawa, I. Komine, N. Mizuno and K. Ohtsu: Route Tracking System by Adaptive Autopilot, Proc. of CAMS'89, pp.77 -82, Copenhagen, Denmark. (1989).

(12) Nguyen, D.H., J.S. Park and K. Ohtsu: Designs of Self-tuning Control Systems for Ships, The Journal of Japan Institute of Navigation, Vol.99, pp.235-245, Japan (1998).

(13) Nguyen, D.H., N. Mizuno and K. Ohtsu: A Modified Pole Assignment Typed Autopilot for Ships, The Journal of Japan Institute of
Navigation, Vol.102, pp.327-337, Japan (2000).

(14) Oda, H, T. Hyodo, K. Ohtsu, M. Ito, N. Hirose, J.S. Park and H. Sato: Designing Advanced Rudder Roll Stabilization System High Power with Small Size Hydraulic System and Adaptive Control, 12th SCSS'99, Hague, The Netherlands (1999).

(15) Ohtsu, K, M. Horigome and G. Kitagawa : A New Ship's Autopilot Design through a Stochastic Model, Automatica, Vol.15, pp.255268, Pergamon, UK (1979).

(16) Ohtsu, K., H. Oda and T. Iida: Challenge to Advanced Optimal Ocean Navigation System (in Japanese), the 13th Dynamic Symposium: Ship Motion and Its Control at Seas, Vol.2, pp.45-91, the Society of Naval Architecture of Japan, Tokyo, Japan (1997).

(17) Takashi, I.: On an Adaptive Dynamic Positioning System for Vessels (in Japanese), The Kansai Society of Naval Architecture, Vol.213, pp.89-96, Japan (1990).

(18) Wellstead, P.E. and M.B. Zarrop: Self-tuning Systems : Control and Signal Processing, John Wiley and Sons Ltd., UK (1991).

(19) Zhou, W.W. : Linear and Nonlinear Recursive Prediction Error Methods in State-Space Models, the 8th IFAC Symposium on Identification and Systems Parameter Estimation, pp. 1092-1099, Beijing, China (1988).

(20) Zhou, W.W. and M. Blanke: Identification of a Class of Nonlinear State Space Model Using the RPE Techniques, IEEE Transactions on $A C$, Vol.34(3), pp.312-316, UK (1986).

(21) Zhou, W.W., D.B. Cherchas, S. Calisal and G. Rohling : Identification of Rudder-Yaw and Roll Steering Model by Using RPE Techniques, pp.93-101 (1989).

\section{Questions and Answers}

Makoto ENDO (Toyama National College of Maritime Technology):

There is no comparison of experimental results between your autopilot and other adaptive autopilots based on other algorithms. What is the main object or the merit to 
use the pole assignment type of autopilot?

Duc-Hung NGUYEN: Many thanks for your discussions.

Well, our work does not deal with the comparison of experimental results between our autopilot and other adaptive autopilots. We have thought of this idea but we had no more chance to carry out full-scale experiments to compare our autopilot with another ones. This task will be done in our future work. As I mentioned above, the main object of using the pole assignment type of autopilot is to assign system poles to desired poles. I think that the merit of using the pole assignment type of autopilot has two points. Now, let's look at the equation (18), this equation is the closed-loop description. According to the pole assignment control theory, the right-handed side of this equation is assigned or replaced by a desired set pole polynomial $\mathrm{T}$ which can arbitrarily be chosen as in the equation (19). Therefore, the first point is that closed-loop equation becomes much simpler. In addition, for a specific case, let's look at the equation (23), the desired set pole polynomial $\mathrm{T}$ is calculated by vibration expressions (23). The second point is that by selecting damping factor, natural frequency and sampling time, the ship's response can be determined by the designer. 